\title{
Abdominal Hernia
}

National Cancer Institute

\section{Source}

National Cancer Institute. Abdominal Hernia. NCI Thesaurus. Code C98700.

The protrusion of abdominal contents through a congenital or acquired defect in the abdominal wall. 